\title{
Creating a Sustainable Business Model in the Construction Firm
}

\author{
Aneta Marichova
}

\begin{abstract}
Every firm today is facing significant problems which are a consequence of the influence of external and internal factors. This necessitates strategic changes in its activities, which focus on the development of the basic elements of intangible assets - people, knowledge and system, whose effective combination allows building competitive advantage and company growth. The main, specific intangible resource of the company is the business model itself, which is the economic basis of the strategic behavior of the company. From this point of view the purpose of the study is: 1) developing a sustainable business model for the construction firm, 2) analyzing the mechanism by which the manager creates and/or develops his own sustainable business model, taking into account the specifics of the construction market.
\end{abstract}

Keywords - business model, construction firm, sustainable development, sustainable construction, sustainable business mode

\section{INTRODUCTION}

Every firm today faces a number of external problems (related to changes in demand, technology and competitive environment), internal problems (rising production and transaction costs, inefficient production in general and the system of vertical connections, etc.) and of course financial problems (declining revenue, declining profits, survival of the company) that are a consequence of the influence of external and internal factors. In addition, it operates in a growing environment globalization, scarcity and rising cost of resources, geographical isolation, the result of company localization and insufficient capacity to adapt to ever smaller, fragmented markets. In practice, this means that traditional sources of competitive advantage, such as cost-based differentiation, the result of economies of scale or scope, have an increasingly limited impact. However, new economic realities create new opportunities and new sources of competitive advantage. They relate to the growing importance of intangible assets, ownership, effective management and use. Intangible assets include first and foremost knowledge, technological know-how, innovations that allow a dynamically developing firm to differentiate and realize competitive advantages. Knowledge as a major resource of the company today, in itself can not create the desired added value and provide sustainable competitive advantages. It must be effectively combined with other intangible and tangible resources / assets that can be defined as specific, complementary to the firm and they generally create new resources and opportunities for corporate growth and development through effective organization and 
management. Such specific resources (usually the result of history, culture, specificity of company development) may be human capacity, organizational, innovation assets, internal relationships, relationships with suppliers, customers, institutions, etc. The development of firm knowledge, innovation, enhances and develops other complementary intangible and tangible resources, and they, in turn, have a positive impact back on them, i.e. there is a constant dynamic connection (defined as dynamic capabilities of the firm).

Intangible resources create the opportunity, flexibility of the company to perceive and develop all new technological and competitive discoveries, to create and offer higher added value for its clients, through creative development, combining, transferring, accumulation of knowledge, experience, but also with protection of its own intangible assets. These are the new "natural" resources of the world economy, which, however, are evolving as a function of management, organizational activities in each company [1]

The main, specific intangible resource of the firm is the business model itself [2], which by definition includes relationships with suppliers, customers, company reputation, cultural values, intellectual property and its protection. Each business model is the economic basis of the company's strategic behavior. It is related to the way a company produces, sells its product, but does not relate to its differentiation, its competitive advantages and does not take into account one of the main factors - competition, which is the goal of the strategy. The business model describes and demonstrates how different parts of a system are synchronized and working to create added value for the customer and the company to generate higher profits. A business model organized and developed on innovation is crucial to the success of a company, which operates under market conditions that are sufficiently different from traditional markets today.

This in practice means that the traditional company model "Price/ Revenue - Cost" is not applicable and managers are required to develop a new model, who has to take into account growing requirements for sustainable development, which includes three aspects social, economic and environmental.

Sustainable development, in particular sustainable construction, requires a radical change in the strategic behavior, organization and management of the construction firm, as well as the development and implementation of a new business model that includes new management processes, production organization that stimulate and support the process of developing and implementing new technologies and new products. From this point of view the purpose of the study is: 1) developing a sustainable business model for the construction firm, 2) analyzing the mechanism by which the manager creates and/or develops his own sustainable business model, taking into account the specifics of the construction market.

\section{THEORETICAL FRAMEWORK TO THE STUDY}

In the last 15-20 years the analysis of the problem "business model of the company" occupies an increasing place in theoretical studies by developing different concepts for business model, sustainable business model, innovation in business model and innovation in sustainable business model [3]. The common in all concepts to define a business model is that he is focused on the way by which the company creates and offers value to its customers, which is a factor for building competitive advantages and realizing the company's goals [4]. In practice the model connects firm resources and distinctive competencies and their development with the opportunities to offer and realize additional value for the client. 
A special place in research occupies analysis of the relationship strategy - business model. The business model is "a conceptual framework that helps to relate a company strategy or the way it competes with its activities and strategy implementation. The business model framework addresses the details of how firm thinks strategically and doing business"[5]. The three main components of this framework are the company's mechanism of creating, offering and realizing higher value added for its customers with a strategy not implemented by current competitors. The strategy of the company and its behavior is related to the way it intends to compete in the market in order to build and realize competitive advantages. The business model is associated with identifying actions in order to put the strategy into practice.In other words, " the business model is a reflection of the company's realized strategy"[6]. In this sense, the business model reveals the logic of the company organization and management of the elements of the system and their interaction, which allows creating, offering and realizing additional value for the clients and provides market advantages. The company strategy is one, though dynamic, but it may have different business models to achieve its goals. On the basis of this analysis, the author assumes that each business model includes actions, decisions that aim to implement the developed company strategy, and are based on the effective use and reconfiguration of the company's resources and competencies, close relationships with participants in the vertical chain that allows the creation, offering and realization of additional value for the client. The dynamics of the external environment necessitate the development, change, refinement of the business model, or the realization of innovations [7]. They are about change in one or more elements of the business model, the relationships between them, or the creation of a new model that creates the higher or new value desired by consumers or offers it in a new way.

Sustainable development (and sustainable construction) requires the development and implementation of a new sustainable business model in which the concept of sustainability is a driving force for the firm and decision making. This model completely transforms the dominant neoclassical model of the company, not simply complementing it with social and environmental priorities [8]. „A sustainable business model aims to create and realize higher consumer and social value by integrating social, environmental and business activities" [9]. In this sense, it is different from the conventional one in the following four aspects:

1) A firm proposal that provides higher added value has measurable environmental, social and economic value.

2) All participants in the vertical chain create and enforce higher standards and requirements for the end product.

3) The company trains, develops innovative and eco-friendly thinking of its clients, informing them about the news, directs and changes their tastes and preferences. The main goal is an overall change in consumer behavior: short-term thinking and planning for longterm thinking and planning decisions.

4) The financial model reflects the appropriate distribution of economic costs and benefits among all actors involved in the business model, taking into account environmental and social impacts on society [10].

The author accepts the following definition of a sustainable business model - it is a model that includes actions and decisions of the company which allow the realization of a sustainable strategy, through the efficient use and reconfiguration of the company's tangible and intangible resources, interaction between all participants in the vertical chain from the beginning to the end of the production process, creating a new product on a circular economy principle, offering and realizing additional economic, social and environmental value for the client, stakeholders and society in general, and building firm competitive 
advantage. Dynamics of the external environment, unexpected environmental, economic and social problems require innovation in a sustainable business model. They aim to provide a stabilized competitive advantage, long-term prosperity of the company, reducing the negative impact on the environment, improving the efficient allocation of scarce resources and ensuring social stability.

According to the author, every successful sustainable business model is developed from „the outside to the inside“. The first step is to analyze and segment the market, selecting the target market and clearly defining what the target customers want and seek. The second step is to analyze the firm's activities, resources, competencies and evaluate the possibilities for creating the desired product and /or the need for change. The third step is to build an effective integrated vertical chain that can only provide stability. The end result of realizing a sustainable business model is to create, offer and realize higher additional economic, social and environmental value for the client and society. It can be measured by a long-term (subjective) evaluation of the consumer for the product being offered, by comparing total costs to acquire the firm product (price) and additional cost, which makes for its use throughout the life cycle with the expectations he had, and objectively, result of comparing total customer value received (sum of product benefits received, additional services, image, etc.) with the total cost of acquiring the product (the amount of the price he pays for the product and the cost of time, energy, etc.) or economic evaluation. Of course it must be added and society's assessment of it, to what extent the product offered provides an increase in the standard of living (comfort) and protection and improvement of the environment (care for the future), provides basic environmental, social and economic services, without endangering the viability of natural, established economic and social systems.

The assessment of consumers and society is direct proof for the success of each business model, the realization of competitive advantages and strategic company goals, and the realized profit (revenue/cost) is indirect proof of its success. The goal of the company should be to gain competitive advantage, which is a factor in making higher profits, but not vice versa. Realized profit and other financial indicators, while easy to use and analyze, are features of operational efficiency that do not always make the company the best. If the assessment is only on the basis of profit, it can be the result of conscious company actions (strategic barriers) that limit the entry of new competitors and lead to monopolization of the market and consequently monopoly profit. More important, however, is the situation in which the company makes a profit, which is the result of knowledge, development of innovations, improvement and refinement of business, introduction of a new business model.

On this basis, the author adopts the following basic elements of a sustainable business model (Figure 1):

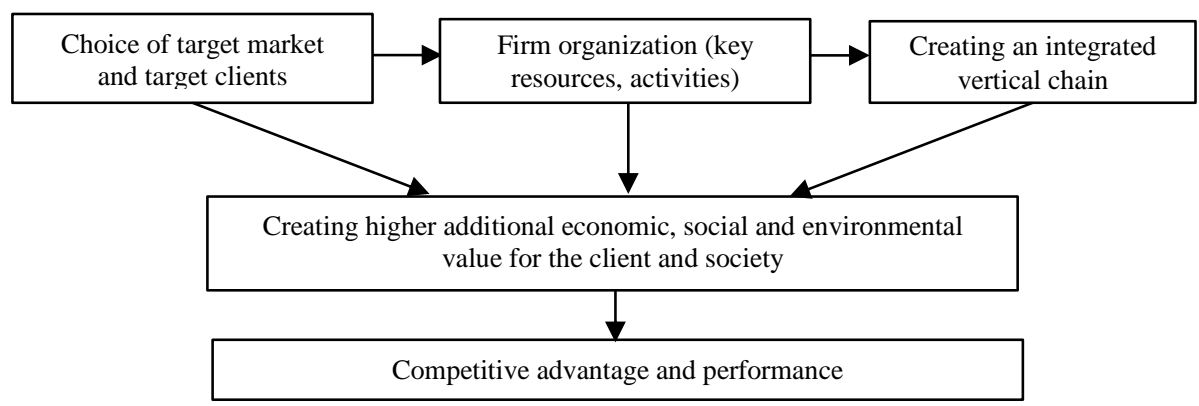

Fig. 1. Elements and relationships in a sustainable business model 
1. Identify the target customers of the firm:

1.1. Market segmentation.

1.2. Choosing a target market.

1.3. Developing working hypotheses that seek and answer the question: What are consumers looking for and how can the company respond to these expressed preferences?

2. Firm organization:

2.1. Evaluation of key firm activities (supply, production, distribution, marketing, after sales service).

2.2. Evaluation of key resources and competences (tangible, intangible, organizational, managerial).

2.3. Solutions for change, development, reconfiguration of activities, resources and competencies to meet the wishes of target customers.

3. Creating an integrated vertical chain, incl. suppliers, clients, investors, financial, marketing, scientific and government institutions:

3.1. Creating higher logistics efficiency by planning, organizing, coordinating and controlling the fulfillment of the obligations of each of the participating companies.

3.2. Creating long-term partnerships through constant connections, relationships and information sharing between the parties involved on the basis of common interest and good personal relationships.

3.3. Building effective links between all actors and effective chain management based on trust and competition.

4. Creating, offering and product realization with higher added economic, social and environmental value to the client and society. This includes all product features that make it easier for the customer or solve their problem in a way other than competitors, allowing for competitive advantages and higher profits for all participating companies.

\section{ANALYZING THE MECHANISM BY WHICH THE MANAGER CREATES AND/OR DEVELOPS SUSTAINABLE BUSINESS MODEL}

The empirical study was conducted among firms operating in the construction market, which first analyzed the influence of the dynamics of the external environment (market) on their strategic behavior and the opportunities for realizing competitive advantages. The conclusions are based on information, collected and processed by a survey, in which managers, employees of the surveyed companies, answer several basic questions [11]:

1) How does the company create and develop its sustainable business model in response to the dynamics of the external environment?

2) What are the steps in creating and developing a sustainable business model?

3) How are the key activities and resources evaluated in each of these phases?

4) How is an integrated vertical control circuit built?

5) What are the difficulties for the construction company in creating new, sustainable business models?

6) What strategies are being developed to support this process?

Creating and developing a successful business model is a function, first and foremost, of the ability of managers to monitor, evaluate and learning, which is also defined as an incoming intellectual capacity of the company. They outline new directions for business development and growth, a function of change in demand and technology, which 
is usually one of the most complex tasks. This process is developed and applied by the senior management team in a specific way, depending on the organizational structure of the company, the established relationships with the external environment, the analytical system of procedures, managerial skills and perceptions created.

First of all, the management team performs constant monitoring, scanning of the dynamics of the environment and processing of considerable volume of information, which will allow to open the opportunities for development. The identification of new opportunities for the development of the company is based on a thorough study of the impact of market and technological dynamics at local and global level. The process includes analysis and detection of latent demand, technology development, as well as analysis of state and regulatory mechanisms, economic and social changes, standards, norms, requirements for sustainable construction, and more. The monitoring process also requires effective market segmentation on appropriately selected segmentation criteria that take into account market and customer specificity, target market selection. The goal of any firm operating in the construction market should be - specialization in project development, which are differentiate from the competitive ones and respond to customers' desires from the target market.

It is especially important to develop working hypotheses, based on the information collected, that seeks and offers the answer to the question: What do consumers want and seek and how can the company respond to these expressed preferences? The hypothesis and response must include an analysis of [12]:

1) The technical features that need to be incorporated into the new product.

2) Determination of a reasonable price for consumers and on this basis determined by the company revenues, costs and profits.

3) Organization of production.

4) Choosing a market target segment to position the company.

5) Determining the mechanism by which the firm will provide higher added value to its customers.

A critical point in the business of companies is precisely this process of developing and testing hypotheses, and therefore it should be carried out by the highest management team. Very often the necessary information for the analysis that underlies and decision making is limited or the company receives it late. This requires the development of a specific system of search, collection and analysis procedures. The interpretation of the information collected requires special knowledge that belongs to individuals, but it is also the result of the accumulated knowledge, experience in the organization as a whole. In order to achieve the desired effect, a synthesis is needed between the knowledge of individuals and the company as a whole organization, through the acquisition, assimilation, sharing of external knowledge with the internal. Providing access to knowledge and innovation, investment decisions and the necessary organizational and structural changes are the basis for successful long-term development of each company and function of a working business model.

The second important and responsible step is to evaluate the capabilities, resources, competencies of the company and the opportunities for development and creation of the desired product by the target customers. This assessment outlines the directions for development through specialization of assets and their complementarity with other tangible and intangible resources inside and outside the company, building integrated vertical systems, investment in research, etc.

The main focus in the activities of managers is the assessment of the discrepancy between current and desired positions, which determines the direction and sources for 
reconfiguration of resources, which will provide the desired future development and positions of the company. If the difference between the desired and the actual situation is relatively small, the company could, through improvement, development, search for new more effective combinations or reconfigure of existing internal resources developed on the basis of past, history, culture, value and experience to reach in a timely and effective manner to the desired positions. $f$ the difference between the desired and the actual situation is relatively larger, then it clearly indicates that the internal opportunities are insufficient or underdeveloped in view of the new challenges in the market, and in this case the company should seek new opportunities from external sources. If the required assets are tangible, they are managed on the basis of long-term contracts with partners or through purchase, acquisition. However, if they are intangible, i.e. can not be bought, acquired from the market, the task of managers is to decide what investments can be made in order to develop them and how to achieve coordination and specialization with other companies on this basis. Developing and implementing actions that can fill the vacuum between the current and desired state of the company often involves complex organizational processes, social relationships that require effective communication and development and other activities within the company - marketing, distribution, and more.

The development of the firm today is based mainly on the development of intangible assets, and the central place in them is the ability of the company to learning and generate new knowledge. Companies recognize the role of creating, acquiring and transferring knowledge as a basis for making informed investment and market-oriented decisions. The investment process includes not only investments and development of new products / processes, but also investments in the development of intangible assets and the development and implementation of a new business model, both functions being effectively integrated within the company organization.

One major problem for managers is the decision to determine the boundaries of the firm's development. Increasing company assets as a result of mergers with other companies in the vertical chain, leading to reduced transaction costs, realizing economies of scale or scope, does not always mean that the company is able to create and offer higher added value to its customers and realize competitive advantages. The realization of the firm objective today can be the result of continuous improvement, development of existing tangible and intangible resources/assets and development of complementary assets, or in short, a high specialization of the company in a given market segment. For these reasons, a major problem for managers is deciding on the scope of activities and pooling assets that allow for complementarity, learning, development of complementary innovations and the creation of an effective business model and management.

In the construction market, it is necessary to improve the level of communication between participating companies, to develop partnerships, whether formally through agreements or simply achieved through informal relationships that allow the creation of Multidisciplinary Teams by investors, architects, designers, contractors, end users right at the beginning of a project, whose main purpose is to create an object, meeting the requirements of sustainable construction. This is a long-term goal that requires a high level of knowledge, competence and interaction between all participants in the construction process.

One of the main obstacles that needs to be overcome to create a sustainable business model is breaking with traditional approach relationships in the vertical chain links and implementing a policy of creating and managing an integrated vertical chain of links based on competition that covers the entire construction process (from production and delivery of materials, production of the next product, to the creation of the end product and 
its realization to the end user). Efficiency is achieved through cooperation and long-term contracts, long-term relationships, continuity of collaboration, exchange of information and trust. The construction and effective management of the integrated vertical chain based on competition is an important factor for stimulating innovation, especially "open innovation", reducing information asymmetry and transaction costs, increasing specialization, developing technologies inside and outside the company and their application in creation of the final construction product.

The final construction products demanded by consumers are a complex system of different elements, components, parts with a strong functional dependence, which largely determines and the need for unificationbetween more independent companies in the vertical chain and allows application and development of best practices in the design, implementation, maintenance and reconstruction of buildings. Standard building practices, led by short-term economic goals often show little concern for energy efficiency or even more so for the economic, social or environmental impact of the built-up area. Sustainable business modelis trying to end these practices by integrating a wide range of design, construction, operational and maintenance practices to provide a healthier life, a better work environment, and reduce environmental impact. An important factor is the development and implementation of Integrated Design Principles - the approach to completed building systems, gathering key entrepreneurs and professional designersto work together from beginning to end. With the traditional design approachthe ability to evaluate a buildingin the initial phase as a whole is quite small. The uncoordinated work of different designers leads to permanent repairs and sometimes the necessary changes are noticed too late, barely when construction begins and removing them can be much more expensive. Therefore sustainability in construction starts from the earliest stages of the projectand requires responsible engagementof all participants in the process: investors and clients, architects, designers, construction firms-contractors and subcontractors, suppliers of raw materials, administrative authorities, lawyers, researchers, which in fact means creating of an integrated vertical chain and substantial changes in the organization, coordination and management of the construction company at all levels.

The transition and/or creation of a sustainable business model by the construction firm in the new dynamic conditions requires significant changes in its organization and management. According to the managers, the organizational changes are aimed at creating a decentralized company structure and developing the specialization.

In the context of constant changes in the environment, moving out of the accepted schemes and models of behavior, would allow them to find a new understanding of the ongoing processes, events, facts and on that basis to better predict and outline the new directions for development - applying the principles of sustainable construction and creating a new product that is sought after by consumers on the basis of the use of new technologies and marketed to new target markets, determined by an effective market segmentation process. These decisions must be accompanied by clear assessments and forecasts of the reactions of competitors, customers, suppliers and government institutions that define and control product standards and general game rules.

As a centralized structure implies isolation of top-level managers from other lower-level units, the main goal is to build a Multidivisional Structure, which requires a modern organization of simultaneous teamwork, rather than consistent development and deployment innovation, decentralization of collection rights, information analysis and decision-making, flexible allocation of responsibilities and tasks, developing an effective incentive system to achieve the desired results, etc. In order to reduce the contradictions between different entities coordination is needed in the company through building internal 
integrated systems of motivation and incentives, reconciling the different goals of different groups, and of the company as a whole and supporting the creation of corporate identity, culture and loyalty. The process of training, assimilation, dissemination and integration of external and internal knowledge is realized through qualification of the staff as the main factor for its stimulation and motivation over a long period. The goal of every company management is to create a well-crafted team of professionals with experience, knowledge and skills. The creation of special skills for working in different units, as well as the creation and management of working teams specialized in different functional activities, allows the successful completion of the tasks set and the achievement of the company goals. All of these actions, coupled with maintaining ongoing links between the company and universities, research institutes and units, are key factors for stimulating initiative, innovative thinking that can ensure everyone's active involvement and the implementation of any valuable idea in the direction of sustainability.

In a dynamic environment, management changes are aimed at improving the relationships between management and all company units, the active participation of all entities and units in the bottom-up company, which ensures adaptation and coordination of internal resources and competences to external changes, through the development of intangible assets, which in turn exert influence and develop tangible assets. The efforts of the managers are also aimed at creating high customer loyalty and maintaining the company's reputation by analyzing the constant flow of information from the market, consumers, competitors, suppliers, for changes in demand, processing of the consumer evaluation data for the company and this base provides quick customer feedback. The role of the leader in making quality managerial decisions, motivation and creating incentives for the employees in the company in order to achieve the set goals is extremely important.

The implementation of these organizational and managerial changes in practice can provide better coordination, integration and reconfiguration of internal resources, development of the firm's distinctive competencies. Its ability to successfully reconfigure its competencies to change the market and new requirements is primarily the result of its ability to further specialize and differentiate in the vertical chain, which increases the share of value added created and increases efficiency and productivity through additional investment in human capital, knowledge and innovation. In addition, it requires a significant change in the company's skills to invest in new relationships, new business models, entering new markets, developing new business lines in the direction of diversification, marketing of new products and services, after-sales services, company infrastructure, learning etc.

According to the managers, the main difficulties in creating and transitioning to a sustainable business model are related to:

1) There is no single clear national concept for sustainable construction [13].

2) There is no single system for the assessment and certification of buildings.

3) Not particularly strong investor interest

4) Inadequate research funding in this regard, lack of learning and knowledge for sustainable

development, sustainable construction, inherent conservatism in the education of architects and civil engineers.

5) Problems with the actual implementation of the regulations, laws and regulations on construction waste management and their recycling and incorporation into the construction works, or circular construction [14].

6) There is no well-defined set of sustainable building practices that can be used in projects. 
7) Information on procedures relating to the integration of environmental, economic, social problems in construction is limited and formally structured.

8) The practical realization of the main idea that sustainable construction is first and foremost a team activity of investors, designers, builders and specialists in building management and maintenance is still too limited. They are responsible for thinking about the ecological, economic and social impact of this new class of construction.

9) Absence of a uniform standard, adequate legal standards developed, manuals for design, construction and maintenance of sustainable construction sites does not allow effective cooperation of all participants in the vertical chain of construction activities and leads to the demotivation of investor, owner, user, designer, builder, site manager, etc.

10) The problems and difficulties of sustainable construction are also linked to financial problems (the higher cost), and especially to the difficulties in estimating the costs at each stage of the life cycle of the construction product, separating the capital costs from those for maintenance (operation), price analysis of sustainable materials, certification costs, evaluation of the return on investment in sustainability technologies.

In addition, it should be taken into account the following feature. Firms are different in their origin, age, history, value and culture, which implies different strategies, goals and different directions of development. There is a relationship between age (an established company or new, now starting business), the internal organization and capacity of the company (large, medium, or small) to change, which is not straight and can hardly be thoroughly analyzed. The age and organization of each company influences its own propensity apply different creation methods and approaches, developing and/or changing the business model. Significant influence in this respect is the managerial perceptions, prudence or propensity to risk, which in general determine the directions of company development and the realization of the desired end results.

A large company has a significant amount of accumulated assets, which have a high price and maintenance costs, and logically imposes the care of managers on their storage, protection and efficient use, which in turn reduces the tendency to innovate in new assets and replace old ones. This often creates obstacles for managers to see potential opportunities for business development, through new radical innovations, generation of new knowledge and change in the used business model. From that point of view it is logical to conclude that lower-resourced firms have less potential threat of loss and are therefore more courageous in making decisions to develop innovations, create complementary products, build effective vertical links, or alliances with other companies, which increases their development opportunities. The goal of every responsible company should be to train and develop innovative and environmental thinking in the organization and management of the entire construction process, on the basis of legislative and regulatory measures, which provides a positive environmental, economic and social impact both in the process of building and in the operation of buildings and facilities.

\section{CONCLUSION}

In recent years, the analysis of the problem "business model of the company" has become increasingly important in theoretical studies. The proposed study is focused on two main problems - developing a sustainable business model and analyzing the mechanism by which a construction firm can create and/or develop its own sustainable business model, taking into account the specifics of the construction market. 
The author assumes that each business model reveals the logic of the firm organization and management of the elements of the system and their interaction, in order to realize the developed company strategy, and to create, offer and realize additional value for the client. Sustainable development, in particular sustainable construction, requires a radical change in the strategic behavior, organization and management of the construction company, as well as the development and implementation of a new business model. The sustainable business model includes actions and decisions of the company that allow the implementation of a sustainable strategy through efficient use and reconfiguration of the company's tangible and intangible resources, interaction between all participants in the vertical chain from the beginning to the end of the production process, creation of a new product on the principle of the circular economy, offering and realizing additional economic, social and environmental value to the client, stakeholders and society in general, and building corporate competitive advantages.

According to the author, every successful sustainable business model is developed from "the outside to the inside". The first step is to analyze and segment the market, select the target market, and clearly define what your target customers want and seek. The second step is to analyze the company's activities, resources, competencies and evaluate the possibilities for creating the desired product and the need for change, and the third step is to build an effective integrated vertical chain. The end result is the creation of a sustainable business model that enables the creation, offering and realization of a product with higher added economic, social and environmental value for the client and society and competitive corporate advantages.

The survey (involving several basic questions) among managers and employees in construction companies, allows the author to draw appropriate conclusions and outline the problems.

Creating and developing a successful business model is a function, first and foremost, of the ability of managers to monitor, evaluate and learning, which are also defined as the incoming intellectual capabilities of the company, which outline the new directions for company development and growth. Using the accumulated experience, knowledge and analytical procedure system, the manager must constantly identify the changes in the environment, analyze the possible alternatives for development and develop complementary strategies (within the conventional ones) with which to successfully adapt to the changes. They are related to investment decisions, innovations in the development of a new product or process, entering new markets, the process of integration, cooperation with other companies, diversifying or deepening the specialization of the company, increasing the effectiveness of vertical connections, training, stimulation and motivation the staff, creating high customer loyalty and maintaining the company's reputation. In practice, this means creating a unified system of organization, management and control that requires the company and each of its employees to be personally involved with clients and build partnerships with them to enable them to find the solution that is optimal to their wishes, based on the latest technologies and the realization of added value.

Sustainable construction sets as a primary goal for every construction company the creation of a sustainable business model as a specific, unique company organization and management of tangible and intangible assets, which will allow it to reveal its unique skills, resources and distinctive competences for creating a construction product with high economic, social and environmental value. 


\section{REFERENCES}

[1] Boons F., Lüdeke-Freund F. (2013), Business models for sustainable innovation: stateof-the-art and steps towards a research agenda, Journal of Cleaner Production, 45 pp. 13

[2] Casadesus-Masanell R., Ricart J.E. (2010), From strategy to business models and onto tactics, Long Range Planning, Vol. 43, pp. 195

[3] Chesbrough H., Rosenbloom R., (2002), The Role of the Business Model in Capturing Value from Innovation: Evidence from Xerox Corporation's, Technology Spinoff Companies, Industrial and corporate change, vol.11. N3, pp. 529-555

[4] Doneva D. (2014), Socio-economic aspects of sustainable development in Bulgaria, Visnyk of the Lviv University, Series International Relations, No Issue 35, pp. 190-199, ISSN ISSN 2078-4333.

[5] Geissdoerfer M., Vladimirova D., Evans St., (2018), Sustainable business model innovation: A review, Journal of Cleaner Production, Vol. 198, 10 Oct., pp. 401-416

[6] Geissdoerfer M., Vladimirova D., Evans St., (2018), Sustainable business model innovation: A review, Journal of Cleaner Production, Vol. 198, 10 Oct., pp. 410

[7] Ivanova V., Sterew N. (2019) From sustainability to a model of circular economy - the example of Bulgaria, Proceedings of INTCESS 2019- 6th International Conference on Education and Social Sciences, 4-6 February 2019- Dubai, U.A.E. pp.757-766, http://www.ocerints.org/intcess 19

[8] Magretta J. (2002), Why business models matter, Harv. Bus. Rev., pp. 86-92

[9] Richardson J. (2005), The Business Model: An Integrative Framework for Strategy Execution, Strategic Change, 17(5-6) 133, January, pp. 135

[10] Schaltegger S., Hansen E., Lüdeke-Freund F. (2012), Business Cases for Sustainability: The Role of Business Model Innovation for Corporate Sustainability, International Journal of Innovation and Sustainable Development, 6(2), July, pp. 112

[12] Stubbs W., Cocklin C. (2008), Conceptualizing a sustainability business model Organ. Environ., 21, pp. 103-127

[13] Teece D. (2007), Explicating Dynamic Capabilities: The Nature and Microfoundations of (Sustainable) Enterprise Performance, Strategic Management Journal, 28(13), pp. 131950. Published online 7 August. http:// www.interscience.wiley.com

[14] Teece D. (2011), Dynamic capabilities: a guide for managers, Strategy, Ivey Business Journal,March-April.

[15] Teece D. (2010), Business models, business strategy and innovation, Long Range Planning, Vol. 43, Iss. 2-3, April-June, pp. 172-194

[16] Osterwalder A., Pigneur Y. (2010), Business Model Generation, Wiley \& Sons, Hoboken

[17] Wirtz B.W., Pistoia A., Ullrich S., Göttel V. (2015), Business models: origin, development and future research perspectives, Long. Range Plan., 49, pp.41

Note:

Aneta Marichova - University of Architecture, Civil Engineering and Geodesy, 1, Hristo Smirnensky Boulevard, 1046-Sofia, Bulgaria (e-mail:aneta.marichova@abv.bg, marichova_fte @uacg.bg) 